\title{
TELEPORTATION OF SARS-COV-2 INFORMATION AND QUANTUM ENTANGLEMENT OF THE COVID-19 PANDEMIC PROCESS (SOME PHYSICAL MEANINGS)
}

Gavrilov Vladimir Yurievich*1, Antipova Tatyana Alexandrovna ${ }^{2}$, Vlasov Yan Vladimirovich ${ }^{3}$, Ardatov Sergey Vladimirovich ${ }^{4}$, Ardatova Anastasia

Sergeevna ${ }^{5}$

1 ORCID: 0000-0001-6964-6086 Samara regional public organization of disabled people with multiple sclerosis. Chief scientific adviser. Corresponding member of the Academy of medical and technical sciences of the Russian Federation.

${ }^{2}$ ORCID: 0000-0001-5499-2170 Samara state medical University of the Russian Federation. Associate Professor of the Department of medical physics, mathematics and informatics.

${ }^{3}$ ORCID: 0000-0002-9471-9088 Samara state medical University of the Russian Federation. Professor of the Department of neurology and neurosurgery. President of the "All-Russian public organization of disabled people with multiple sclerosis".

4 ORCID: 0000-0002-2644-5353 Samara state medical University of the Russian Federation. Associate Professor of the Department of traumatology, orthopedics and extreme surgery named after academician A. F. Krasnov. Head of the Department of traumatology and orthopedics №1 of SamSMU clinics.

${ }^{4}$ ORCID: 0000-0003-3329-9427 Samara state medical University of the Russian Federation, resident of the Department of medical rehabilitation, sports medicine, physiotherapy and balneology. 


\section{*Corresponding Author: Vladimir Y. Gavrilov Samara regional public organization of disabled people with multiple sclerosis. Samara, Russia Email:}

ya.gavr-72-41@yandex.ru

\section{ABSTRACT}

In their previous works, leading their history since 1988, the authors of this article have repeatedly conceptually shown and experimentally verified the results of research on the teleportation of information between macro objects. Early author's works were performed during the existence of the Russian Federation as a country called the Union of Soviet Socialist Republics (USSR). Some of which were marked "Top Secret" - links further down the text. Since they were performed under the supervision of the relevant special services and further "Department of external relations of the Russian Academy of Sciences". The authors used numerous examples to demonstrate the possibility of teleportation of information in macro-systems, including ecosystem, biogeocenotic levels, and then tissue and organism levels. Successful experimental verifications occurred only in cases when all the principles and rules laid down in the theory of quantum information, applied to biological objects, were correctly combined. Namely, the preparation of cascades of entangled States was performed both on the mental and somatic levels. In full accordance with the principle of complementarity and taking into account the fact that the observer and the observed are actively connected by the sum of similarities. In addition, the role of the classical communication channel in this process was performed by carrier electromagnetic fields modulated by a useful signal. This signal represented a cast of the simulated experimental process. An example of a real COVID-19 pandemic is the verification of author's works in nature on a biogeocenotic scale. And certainly with anthropogenic - so to speak-participation.

KEYWORDS: CoViD-19 pandemic, quantum teleportation, quantum nonlocality, macroscopic entanglement, standing waves of Schumann resonances, Louis de Broglie waves, quantum theory of gravity, evolution. 


\section{INTRODUCTION}

In this article, the authors would like to consider the mechanisms of quantum teleportation at the mesoscopic level in macrosystems, using the example of quantum-wave mechanisms of the evolution of the CoViD-19 pandemic, in the form of the SARS-CoV-2 (2019-nCoV) coronavirus in 2020. In fact, it implies a certain information exchange in the planet's biogeosphere [1-16]. In their previous works on the study of quantum information teleportation between macroscopic objects and systems [17-61], the authors considered both the mechanisms of such interaction at the level of natural biogeocenoses [17 - 19], and some issues related to the study of processes based on new physical principles of action [50 - 61]. Early author's works [17-19] were performed during the existence of the Russian Federation - as a country called the Union of Soviet Socialist Republics (USSR). And were marked "Top Secret" [18, 19]. And in an obvious natural-like form, mechanisms based on new physical principles are shown in [53] exactly as it could occur naturally when biological objects interact with each other and the environment $[7,8,9,53,65-68,78]$ within the framework of biogeocenotic relationships in ecosystems. The authors would also like to emphasize that this article was written as an urgent and timely commentary on the work [87] and was created on its motives. It should also be noted that this work is not about the CoViD-19 pandemic, in the personification of the SARS-CoV-2 coronavirus. This work is about the mechanisms of possible quantum - wave nonlocal nature of the processes of interaction between material bodies and biological objects .

In fact, this article should be considered as a note on possible quantum-wave mechanisms of evolution, both in the general sense and in particular cases of pandemics and nosological forms. And within this note - on the example of the CoViD-19 pandemic of the severe acute respiratory syndrome coronavirus (SARSCoV-2//2019-nCoV). The authors are not inclined to talk about the criteria of natural selection. These criteria are unknown to us. We can assume only one thing: the step s of natural selection seem to have some nano-, bio-, info-, cogno - (NBIC) 
format. Therefore, this article is legitimate only as a sum of assumptions based on the sum of previous publications [17-61: biogeocenotic and ecosystem levels [1719], physical and technical aspects [20 - 47, $51-61]$, based on new physical principles of action, as well as some synthesis of all previous meanings [49-51].

\section{MAIN CONTENT}

So: in some favorable electromagnetic environment, which is the natural geomagnetic background of the planet, there is a phenomenon of formation of standing waves with a frequency $\mathrm{f}=7.83 \mathrm{~Hz}$, as well as their harmonics at frequencies $\sim 14,20,26,32 \mathrm{~Hz}$ between the earth's surface and the ionosphere. These are the so-called Schumann resonances [79-81], which are, apparently, nothing more than a natural "laboratory" for the preparation and preservation of entangled states where information is present in a non-local and collapsed form that makes up the entire possible completeness of SARS-CoV-2 coronavirus manifestations in groups of events based on the nosological form of CoViD-19 pandemic. The manifestation in a variety of clinical forms of the picture of coronavirus disease is the localization and deployment of the quantum picture on the" screen " of the world of classical objects. Just as the information that was originally recorded in a non-local, collapsed form on a solid-state drive is localized and deployed on a computer monitor. In parallel to the electromagnetic field of standing waves (Schumann resonances*- fermion source), there is soft $\mathrm{x}$-ray radiation, which is a carrier of Louis de Broglie waves [82 - 85], as a source of bosons, which are a component of the natural version of the flow of unlikely events, assuming a certain interaction of biological objects with the environment, a quantum leap of events of some small probability to events that are statistically more reliable [48, 49, 87].

The waves of Louis de Broglie can be with different individual information loads apparently. It is a complete set of CoViD-19 manifestations in this case. The SARSCoV-2 (2019-nCoV) coronavirus appears to be a virus of the NBIC format 
generation. However, a non-local information pool will appear as a disease with a certain clinical picture and accept classic features only under certain condit ions of interaction of a biological object with the surrounding environment. We don't know what the terms of this interaction are.

Therefore, the recommendations of a quarantine nature seem very logical in order to exclude the possible decoherence of undefined states, which, in fact, determine a certain modality, the timbre of these possible premorbid states - from the determinative adverb "almost". Decoherence will lead to the collapse of the wave function and the transition of the quantum system "biological object-external environment" to one of the eigenvalues of the probability density matrix for the flow of events. Some variants of physical and technical implementation of these natural mechanisms are considered in [50-61, 69]. A certain nature-like model based on new physical principles of action is shown by us in [53].

* Note: the Earth and its ionosphere is a giant spherical resonator, the cavity of which is filled with an electrically conducting medium. If the electromagnetic wave that has appeared in this environment after rounding the globe again coincides with its own phase (enters into resonance), then it can exist for a long time.

The basis, or main, for these resonances is a wave with a frequency of $7.83 \mathrm{~Hz}$ (cycles per second), which is a standing wave in the resonator between the ionosphere and the Earth. Since this rhythmic pattern lies within human brain ranges, various authors have suggested that this aspect of the earth's electromagnetic field may act as a kind of global mind... [https://skladchik.com/threads/Resonance-Schumann-Pulse-Earth-full-upgradeimproved-version.177416/].

The authors believe that this article was written as an urgent and timely commentary on the work [88] and was created on its motives. It should also be noted that this work is not about the CoViD-19 pandemic, in the personification of the SARS-CoV-2 coronavirus, but about the mechanisms of the possible quantum 
- wave nonlocal nature of natural selection processes on the example of current events.

The authors are planning to publish a paper in the near future that shows the possibility of technical implementation of the described mechanisms on the example of the functioning of a nature-like laboratory model, based on research conducted earlier in [17-61].

\section{A VARIANT OF IMPLEMENTING SOME THERAPEUTIC EFFECT - BASED ON THE MATERIALS [52-55]}

The principle of organizing a certain therapeutic effect in the variant presented in Fig. 1 is implemented as follows. The subject (1) (in this case, the patient) is placed inside a device similar to a magnetic resonance imaging (MRI) machine (2). An installation like a tomograph is needed to create a favorable electromagnetic environment that simulates the natural geomagnetic background of the planet in the combination of Schumann resonances, Louis de Broglie waves (soft x-ray - in the range of 0.1 to $10^{-10} \mathrm{~m}$ ) and a broadband emitter of UHF or EHF waves modulated by the necessary information - to simulate events and processes specified by the operator. The impact is carried out in a forced mode, in the form of an alternating electromagnetic field with a frequency $\mathrm{f}=7.83 \mathrm{~Hz}$, as well as their harmonics at frequencies $\sim 14,20,26,32 \mathrm{~Hz}$ around the object of impact (1). Inside the electromagnetic field of Schumann resonances, which are a "laboratory" for the preparation of entangled states, it is necessary to create a favorable environment for transmitting to the object of influence (1) the information component that is linked under the influence of Schumann resonance fields. The role of such a medium is played by soft $\mathrm{x}$-ray radiation (4), which is a carrier of Louis de Broglie waves, as a source of bosons, which are a component of the natural version of the flow of unlikely events in the forced mode, which assumes a statistical quantum leap of events of low probability to events that are statistically more reliable [86]. The x-ray emitter (5) is controlled by a modulator (6) operating in both continuous 
and pulsed modes. The stimulating effect (7) is carried out by means of an electromagnetic field radiated by a broadband emitter (8), whose operation is controlled by a modulator (9). Modulators (6) and (9) are synchronized for all wave parameters and are information entangled states. The modulated broadband emitter puts an information component into the configuration of the electromagnetic fields by its radiation. This information component was obtained using the previously described schemes [52-55] and principles [17-61]. As a result, there is an increment of some mass of information in the original system presented in the figure. This system simulates the phenomenon of information accretion in laboratory conditions $[88,89]$.

Based on the above, it seems possible that: "gravity is a product of "quantum entanglement", and not "space curvature" [90 - 92]. "Therefore, it is possible to adequately describe macroscopic objects and gravitational effects typical of General relativity using quantum mechanical tools... And ... quantum entanglement is a condition of energy density, and this condition should satisfy the future theory of quantum gravity. Thus, entanglement and gravity are dually related: what appears as a quantum entanglement in a small-dimensional space becomes a gravitational interaction in a larger-dimensional space. If this interpretation is correct, then a significant step towards the creation of a quantum theory of gravity has been made" [92]. 


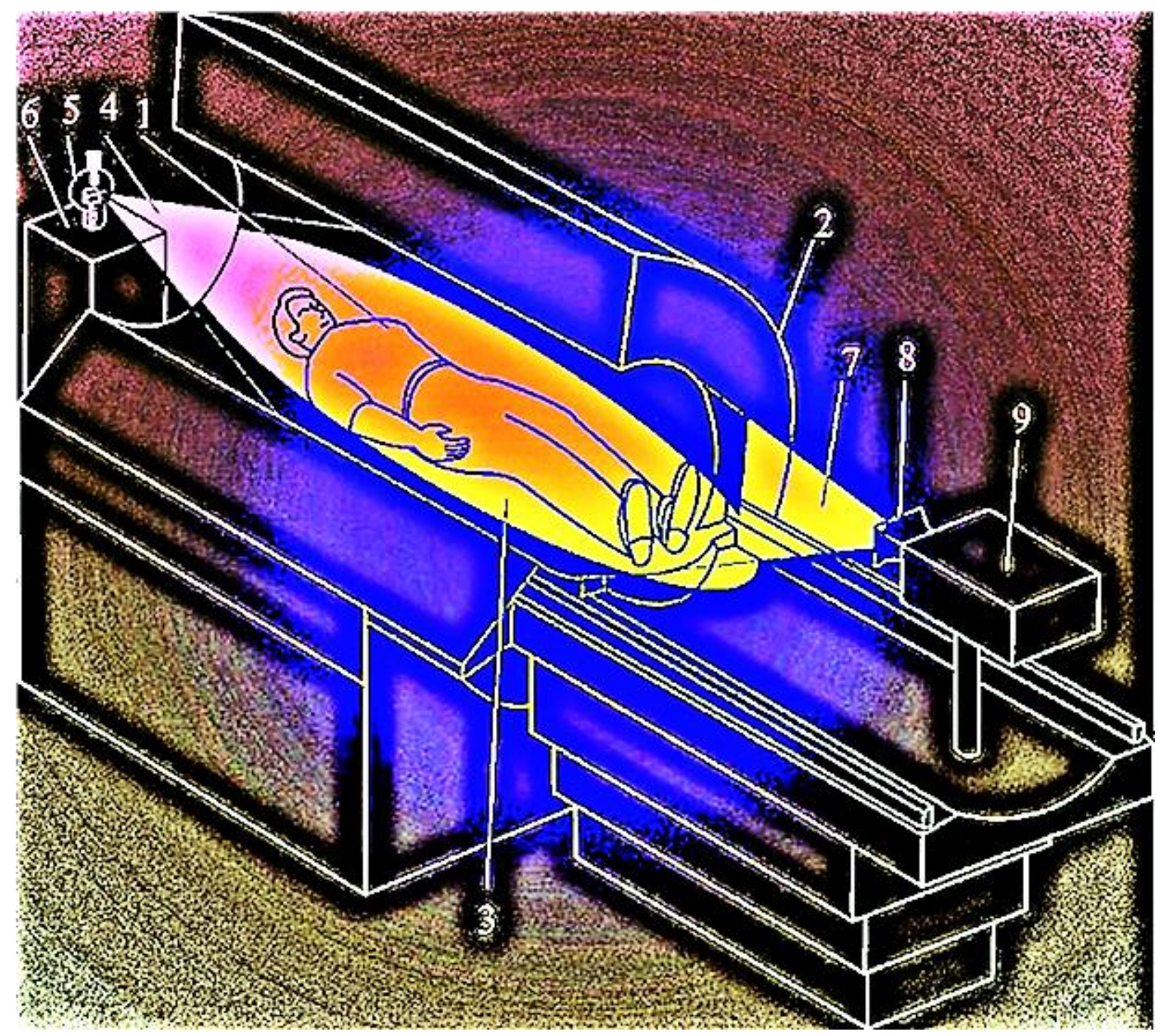

Figure 1. Variant of implementing a certain therapeutic effect based on new physical principles of action

The authors plan to consider the diffraction problems, conceptual and technological details, as well as the interdisciplinary convergence of mechanisms for implementing the above-described technotron model in upcoming publications.

\section{CONCLUSION}

In this article, the authors considered some ontological possibilities of telep ortation of quantum information at the biogeospheric level on the example of the CoViD-19 pandemic. The scientific novelty of the work, according to the authors, is that for the first time a hypothetical possibility of forming stable cascades of entangled quantum states at the macro level and, possibly, on the basis 
of mechanisms equivalent to the phenomenon of quantum gravity is considered. Quantum gravity seems to be an adequate description of macroscopic objects and gravitational effects typical of General relativity using quantum mechanical tools. Quantum entanglement is a condition of energy density, and, therefore, a kind of "preservative" of prepared entangled states, which allows these states not to undergo random decoherence when interacting with the external environment. The phenomenon of decoherence occurs only when necessary and sufficient prerequisites occur, which are contained in certain conditions and under certain circumstances. It is then that Louis de Broglie waves modulated by certain information of natural or artificial geophysical origin can collapse to one of the eigenvalues of the information matrix. And one of these values is the activation of the clinical picture of virology in a certain sample of biological objects. This information matrix is "preserved" - as cascades of entangled states - in the depths of standing waves of Schumann resonances with the highest energy density. This is how wave functions become real virulent particles of the SARS-CoV-2/2019$\mathrm{nCoV}$ reduced to corpuscles of one of the diagonal values of the information matrix in the acts of cascades of certain decoherences. Before the corresponding act of decoherence, the virulence of quantum viral particles is only a probability that is in full accordance with the quantum-wave dualism of the hypothetical process described. Thus, entanglement and gravity are dually related: what appears as a quantum entanglement in a small-dimensional space becomes a gravitational interaction in a larger-dimensional space. Thus, SARS-CoV viruses-2//2019-nCoV are activated as virulent particles only when biological objects interact with the environment in some way. What and the nature of this interaction is, we cannot say for sure. Which determines the biogeospheric and ecosystem aspects of these meanings in the NBIC convergent nature of this scientific work. Some features of the impact, interaction and aftereffect of various types of virus on the immune system are discussed in: [94]: «The outbreak of SARS-CoV-2 in Wuhan, China caused a pandemic of COVID-19. However, it remains enigmatic why the mortality rate is variable among countries. Here we show that at least three types 
of SARS-CoV-2 virus, type S, K, and G. have spread globally and formed complex infectious trends in terms of transmissibility and virulence. Type K establishes herd immunity and protects against the most virulent type G. Immunity to type $S$ is involved in aggravating type $G$ infections through antibody-dependent enhancement (ADE)». This is confirmed indirectly by the mechanisms and features of the evolutionary dynamics of the coronavirus described above in the arena of current geophysical and biophysical events.

\section{GENERALIZATION}

The term quantum field was formed in physics as a synthesis of representations of physical fields like probability fields and the Faraday — Maxwell electromagnetic field, described in quantum mechanics by wave functions. It is worth noting that physical fields were introduced when it became necessary to completely abandon the principle of instantaneous action of forces, which existed in Newton's mechanics. It was introduced that the space between interacting particles (for example, two electric charges) is completely filled with a field. It is the carrier of the interaction of particles (from one to another), and the transfer occurs at a certain speed. When transmitting an electromagnetic field, all actions are sent from one charged particle to another moving at the speed of light and serves as a carrier for the electromagnetic interaction between the particles. Taking into account quantum fields, there is a process of transmitting the interaction, it comes in quantum portions, where the latter are already elementary particles. They have fixed characteristics of mass, charge, spin, etc. Similarly, on the one hand, interacting particles have common quantized characteristics of mass, charge, and spin, and on the other hand, the interaction between them is transmitted by a quantum field of a certain type with quantized characteristics. Quantum fields include the known physical interactions discussed below in terms of their possible participation in the teleportation of quantum information at the macro level and participation in the creation of space-time itself [95 - 97].

\section{Strong interactions (microscopic level):}

Quantum theory for the strong interaction also consists in the increment of the mass of information teleported by flows (cascades) of entangled baryons and mesons constructed from quarks. They interact by exchanging gluons that have mass 0 and spin 1 .

2. Electromagnetic interactions (mesoscopic level): 
Electromagnetic interaction refers to fundamental interactions. And stands in line with the gravitational, weak and strong interactions. The world that surrounds us is a manifestation of electromagnetic interaction. A large number of forces in mechanics have an electromagnetic nature (forces of tension, elasticity, etc.). Charged particles are sources of electromagnetic fields. Particles that do not have a charge (neutral) interact with such a field due to a complex internal structure or quantum effects. This distinguishes the electromagnetic field from the gravitational field, which acts on all particles. But due to the electromagnetic interaction, there are atoms and molecules, because they are" connected " by electromagnetic forces. Therefore, the electromagnetic interaction is the basis of all existing phenomena on Earth. The chemical forces that unite molecules from atoms are also electromagnetic in nature. The strength of the electromagnetic interaction is much greater than the gravitational one. What distinguishes the electromagnetic from the weak and strong interaction is that its radius of action is infinite. The ability of the electromagnetic interaction to manifest at infinity is explained by the lack of mass in the photon, which is the carrier of this interaction. However, the mass of a moving photon is determined using Einstein's formula, which establishes the equivalence of mass $\mathrm{m}$ and energy $\mathrm{E}$, i.e. $\mathrm{E}=\mathrm{mc} 2$.

The electromagnetic interaction retains its parity with respect to space and charge. This is another difference between the electromagnetic interaction and the weak interaction. And the electromagnetic interaction does not preserve the isotopic spin - this is the difference from the strong interaction.

- From the point of view of classical electrodynamics: interference-results in an interference pattern (hologram). That is, to a quasi-classical object representing a holographic superposition of probable States in the Schumann resonance field [79-81], where the sum of certain conditions creates space-time [95-97].

- From the point of view of quantum electrodynamics: depending on the variants of interaction of a biological object with Louis de Broglie waves [83-86], which carry full information about CoViD-19. All this is superimposed on the matrix of cascades of entangled States located in the field of Schumann resonances. Which can lead to the collapse of the wave function (covid-19 pandemic) to one of the eigenvalues (SARS CoV-2). That is, from the point of view of a hypothetical observer, the interaction of his gaze with this set of holograms occurs - as if at a different angle of incidence of the reference wave on the carrier of these contents. What causes the manifestation of the disease - in its different variations and forms of manifestation of the clinical picture, or does not cause it.

3. Weak interactions (mesoscopic level): 
Quantum theory for the weak interaction is analogous to quantum electrodynamics. In physics, the beta decay of elementary particles (for example, neutrons) and nuclei, where the birth of positron-neutrino or electron-neutrino (anti-neutrino) pairs, the capture of muons or electrons by nuclei, and the scattering of neutrinos located on protons, electrons, or in the nuclei of atoms (there are similar processes of weak electron scattering), are referred to as weak processes. Given the quantum field theory, the elementary act of weak interaction was the process of the birth of a nucleon (neutron or proton), as well as an electron (Tau meson, muon) of a heavy neutral (Z0), charged (W+, W -) and a boson, which instantly decays into a pair of particles. The heavy intermediate boson serves as a similar transmission link as it is in the electromagnetic process of the virtual gamma quantum or Louis de Broglie waves ( $\mathrm{x}$-ray radiation of the geophysical background). In contrast to the latter, bosons also have a huge mass, and the interaction radius, which turns out to be quite small, is about 10-17 centimeters. This is the radius of the weak interaction. At the same time, the fact that the physical picture of the weak and electromagnetic interactions is similar, helped physicists create a General theory where the two interactions are combined into a single electroweak, at fairly high particle energies. There is a difference between them during the transition from large to small energies, but in the sphere of high energies it actually disappears.

4. Gravitational interactions (macroscopic level):

From the point of view of the topology of the Poincare-Perelman theorem [99102]: the object (the wave of the CoViD-19 pandemic) acquires in its nested state the dimensionality that is inherent in the medium (space) of the manifestation of the now SARS - CoV-2 virus.

5. Unified field theory:

- Heuristic meaning: the process of incrementing the mass of information on an object (accretion), by attracting congruent physical sense modes from the surrounding space, by the mechanism of the «strange attractor»

- When accretion of information from the background of a Louis de Broglie plasma to a material medium that has its own magnetic field, the accretion mechanisms are determined by the magnetohy drodynamic interaction of this background with the magnetic field of Schumann resonances.

- The interaction carrier is a heavy intermediate boson of the virtual gamma quantum. Or the waves of Louis de Broglie - a natural soft xray of the geophysical background. The laboratory and storage of information in cascades of entangled States are Schumann resonances. 
- Louis de Broglie waves are a weak component of the process (information and energy components; a catalyst for decoherence directions)

- Schumann resonances - electromagnetic component (holographic probability matrix).

- The quark composition of the two previous components determines the strong component of the process (the microscopic comp onent of the material environment is the source of accretion of matter at the mesoand macro-levels).

Quantum gravity and in a General sense, gravity-in a heuristic sense-is the interaction of cascades of entangled quantum States of all the listed components of certain information flows at the macro level-in their system combination and interaction (information matrix of probabilities).

Quasiparticles of the electromagnetic field, described as quanta of collective excitations in multiparticle systems (for example, in condensed media), can also carry spin and be classified as bosons and fermions. In particular, bosons are phonons ("sound quanta"), magnons (quanta of spin waves in magnets), and rotons (excitations in superfluid helium-4).

This is the system combination and interaction of cascades of entangled States in the information matrix of probabilities that is the reason for the ap pearance of the space-time continuum in its classical form [95 - 97].

6. Hierarchy and synarchy of interactions:

The microcosm (Suprimir) strong interactions is of the macrocosm (Infraero) gravitational interactions source material. And the macrocosm of gravitational interactions is a source of information for the micro-supramir-through weak interactions. In our case, these are Louis de Broglie waves. Mesomir is a link between information and matter - through the energy of the electromagnetic field that entangles all processes in a non - local continuum [70 - 77]. In our case, these are Schumann resonances. Which, under certain conditions, manifests its local (diagonal) variants of event realization, based on its own probability matrix. Variants of realization of certain events depend on certain conditions of interaction of information flows of Louis de Broglie waves with the hierarchy of cascades of entangled States in the field of Schumann resonances. When an object interacts with the environment in the form of the components listed above.

Some mathematical apparatus of the processes described above is currently presented in the necessary and sufficient form in [102]. 


\section{REFERENCES}

1. S. M. Korotaev, N. M. Budnev, V. O. Serdyuk, Yu. V. Gorokhov, E. O. Kiktenko, A. I. Panfilov. BAIKALEXPERIMENT ON OBSERVATION OF LEADING NON-LOCALCORRELATIONS OF LARGE-SCALE PROCESSES//Bulletin of the Bauman Moscow state technical University. Ser. "Natural science". 2014. No. 1. Pp. 35 - 53 [Electronic resource] URL: http://vestniken.ru/articles/178/178.pdf

2. S. M. Korotaev, N. M. Budnev, V. O. Serdyuk, Yu. V. Gorokhov, E. O. Kiktenko, A. I. Panfilov. BAIKALEXPERIMENT ON OBSERVATION OF LEADING NON-LOCALCORRELATIONS OF LARGE-SCALE PROCESSES//Bulletin of the Bauman Moscow state technical University. Ser. "Natural science". 2014. No. 1. Pp. 35 -53 [Electronic resource] URL: http://vestniken.ru/catalog/phys/hidden/178.html

3. RUSSIAN INTERDISCIPLINARY TEMPOROLOGY SEMINAR PROGRAMIN THE CURRENT SEMESTER// INSTITUTEFOR TIME NATURE/COPYRIGHT @ 2020 INSTITUTE FOR TIME NATURE EXPLORATIONS. ALL RIGHTS RESERVED [Electronic resource] URL: http://www.chronos.msu.ru/en/updates/laboratoriya-kafedra-korotayev/korinvestprogr

4. OBTAINING ENTANGLED QUANTUM STATES//INFOPEDIA.SU 2017-02-10 [Electronic resource] URL: https://infopedia.su/18x8dc7.html

5. The POSSIBILITY of CONTROLLING the RATE OF biodegradation of POROUS SILICON NANOPARTICLES IN LIVING CELLS is SHOWN// WEBSITE of the RUSSIAN ACADEMY of SCIENCES [Electronic resource]URL: http://www.ras.ru/news/shownews.aspx?id=76217c70c44d-4782-bea2-392359b893b2\#content 
6. Quantum entanglement turned into glue for DNA// NNN-Site about nanotechnologies № 1 in Russia// - [Electronic resource] URL:

http://www.nanonewsnet.ru/news/2010/kvantovaya-zaputannost-obernulaskleem-dlya-dnk

7. David Coles Lucas C. Flatten Thomas Sydney Emily Hounslow Semion K. Saikin Alán Aspuru-Guzik Vlatko Vedral Joseph Kuo-Hsiang Tang Robert A. Taylor Jason M. Smith David G. Lidzey A Nanophotonic Structure Containing Living Photosynthetic Bacteria//Wiley Online Library/ (C) 2017 The Authors. Published by WILEY-VCH Verlag GmbH \& Co. $\mathrm{KGaA}$, Weinheim [Electronic resource] URL: https://onlinelibrary.wiley.com/doi/full/10.1002/smll.201701777

8. C Marletto1,D M Coles2, T Farrow1 and V Vedral Entanglement between living bacteria and quantized light witnessed by Rabi splitting/ Journal of Physics Communications Volume 2, Number 10 [Electronic resource] URL: https://iopscience.iop.org/article/10.1088/2399-6528/aae224/meta

9. Quantum entanglement was created for the first time Inside a biological system.// HIGHTECH.FM 2017-06-01 [Electronic resource] URL: https://hightech.fm/2017/12/06/quantum-biological-system

10. RP Photonics Encyclopedia (formerly the Encyclopedia of Laser Physics and Technology) / / [Electronic resource] URL: http://www.rpphotonics.com/перевод Ивана Хахалина

11. Jennifer Lin, Matilde Marcolli, Hirosi Ooguri, and Bogdan Stoica Locality of Gravitational Systems from Entanglement of Conformal Field Theories// PHYSICAL REVIEW LETTERS Vol. 114, Iss. 22 - 5 June 2015 
[Electronic resource] URL:

https://journals.aps.org/prl/abstract/10.1103/PhysRevLett.114.221601

12. Jennifer e Lin, Matilde Marcolli, Hirosi Ooguri, and Bogdan Stoica Locality of Gravitational Systems from the Entanglement of the Conformal Field Theories//PHYSICAL REVIEW LETTERS Vol. 114, Iss. $22-5$ June 2015 [Electronic resource] URL:

https://journals.aps.org/prl/abstract/10.1103/PhysRevLett.114.221601

13. How Spacetime is built by Quantum Entanglement: New Insight into Unification of General Relativity and Quantum Mechanics// Kavli Institute for the Physics and Mathematics of the Universe, The University of Tokyo/ This website is GDPR compliant 27/05/2015 [Electronic resource] URL: https://www.alphagalileo.org/en-gb/Item-

Display/ItemId/124827?returnurl=https://www.alphagalileo.org/en-gb/ItemDisplay/ItemId/124827

14. Putenikhin P. V. Quantum teleportation: detailed analysis// SAMLIB. RU 02/11/2013 [Electronic resource] URL: http://samlib.ru/p/putenihin p w/teleport.shtmlПутенихин Петр Васильевич (pe_put@rambler.ru)-Путенихин П.В.m55@mail.ru

15.Putenikhin P. V. Analysis of bell's conclusions on the EPR paradox [Electronic resource] URL: http://samlib.ru/p/putenihin p w/bell.shtml Путенихин Петр Васильевич (pe put@rambler.ru) - Путенихин П.В. $\underline{\text { m55@mail.ru }}$

16. Vetlugin A. N. SPATIALLY MULTIMODE QUANTUM MEMORY for QUANTUMINFORMATION PROBLEMS / / Dissertation for the degree of candidate of physical and mathematical Sciences. Federal state budgetary educational institution of higher education "SAINT PETERSBURG STATE 
UNIVERSITY". Specialty 01.04.05 - "Optics". Saint Petersburg-2016 [Electronic resource] URL:

https://disser.spbu.ru/files/disser2/disser/cCQvn78VLD.pdf

17. Gavrilov V. Yu. Concept of EcoFund of biological balance of ecosystems of reservoirs of the Middle Volga basin [Text]// Introduction, acclimatization, protection and use of plants: Intercollegiate collection. Kuibyshev: KSU, 1988. - P. 103-110

18. Gavrilov V. Yu. Phytocenotic features of the emergence of risk areas of adventivization... [Text]// p. s. of the USSR Academy of Sciences № 0239 of 10.09.83 (item 48, 51) - with a stamp 158-R Top Secret, 1988.

19. Gavrilov V. Yu. a Brief overview of the possibilities of modern phytocenology - in the aspect of creating biological (ecological) weap ons... [Text]// p. s. of the USSR Academy of Sciences № 0239 of 10.09.83 (item 48, 51) - with a stamp 158-R Top Secret, 1989.

20. Pat. 1808139 USSR, G 09 In 23/28. Method of modeling heart block [Text] / V. Yu. Gavrilov, V. M. Gromov, V. I. Kovalkov [et al.]. - no. 5046010/14; publ. 08.06.92; publ.07.04.93. bul. no. 13 (76).

21. Gavrilov V. Yu. On the issue of compliance with a number of conditions for bioinformatic translation [Text] // Bulletin of new medical technologies: Materials of the first international Symposium "Biophysics of fields and radiation and bioinformatics"(Yasnaya Polyana-96), Tula, 1996. - Vol. 3. No. 4. - P. 21

22. Gavrilov V. Yu., Keltsev V. A., Neganov V. A. Endovascular method of blood laser irradiation [Text] // Bulletin of new medical technologies: 
Materials of the first international Symposium "Biophysics of fields and radiation and bioinformatics" (Yasnaya Polyana-96), Tula, 1996. - Vol. 3. No. 4. - Pp. 49-50.

23. Gavrilov V. Yu., Limareva L. V., Makhova A. N., Neganov V. A. Cytomorphological analysis of the effect of laser radiation on the vital activity of Ehrlich's sarcoma [Text] // Bulletin of new medical technologies: Materials of the first international Symposium "Biophysics of fields and radiation and bioinformatics" (Yasnaya Polyana-96), Tula, 1996. - Vol. 3. No. 4. - P. 50-51.

24. Gavrilov V. Yu. Modeling the dynamics of test objects under remote influence of emitters and sonars [Text]// Bulletin of new medical technologies: Proceedings of the first international Symposium "Biophysics of fields and radiation and bioinformatics" (Yasnaya Polyana-96), Tula, 1996. - Vol. 3. - No. 4. - Pp. 58-59

25. Gavrilov V. Yu., Danilov A. A., Kalinin M. G., Neganov V. A., Pyatin V. F. Influence of EHF radiation on human brain activity [Text] // Abstracts of reports and reports of the VI International conference "Electrodynamics and microwave and microwave technology" - issue 3 (24). Moscow, 1999. - Pp. $132-133$

26. Volostnikov V. G., Gavrilov V. Yu., Danilov A. A., Kalinin M. G., Keltsev V. A., Loktev I. V., Matveev I. V., Neganov V. A., Osipov O. V., Pyatin V. F. Practical aspects of interaction of fields with living matter [Text] // Abstracts of the VI Russian scientific conference "Faculty, researchers and postgraduates" - part I. Samara, 2000. - P. 39 
27. Gavrilov V. Yu., Danilov A. A., Kalinin M. G., Neganov V. A., Pyatin V. F. Some aspects of the influence of EHF radiation on the brain's rhythmogenesis [Text]// Abstracts of the VI Russian scientific conference "Faculty, researchers and postgraduates" - part I. Samara, 2000. - P. 40

28. Gavrilov V. Yu., Danilov A. A., Kalinin M. G., Neganov V. A., Osipov O. V., Pyatin V.F. Concept of organization of human brain activity on the basis of a holographic model of the brain [Text]// Abstracts of the VI Russian scientific conference "Faculty, researchers and postgraduates" part I. Samara, 2000. - P. 41

29. Gavrilov V. Yu., Danilov A. A., Kalinin M. G., Chugunov V. V. KVCH generator with wide-range frequency tuning [Text]// Abstracts of the VI Russian scientific conference "Faculty, researchers and postgraduates" part I. Samara, 2000. - P. 42

30. Gavrilov V. Yu., Danilov A. A., Kalinin M. G., Matveev I. V. Bases of the working hypothesis of Biophysics of the "great Union" in biological systems [Text] // Abstracts of the VI Russian scientific conference "Faculty, researchers and postgraduates" - part I. Samara, 2000. - P. 44

31. Gavrilov V. Yu., Kuzmin O. A., Osipov O. V. Bioinformatic approaches to managing the behavior of biological objects [Text]// Abstracts of reports and reports of the II scientific and technical conference "Physics and technical applications of wave processes". Samara, 2003. - P. 383.

32. Gavrilov V. Yu., Osipov O. V. System of technological solutions for stabilization of remissions in dysthymic and addictive States, as well as the transcendence of death, analgesia of incurable patients, treatment of a wide range of psychosomatic nosological forms and premorbid States [Text] // 
Abstracts of reports and reports of the II scientific and technical conference "Physics and technical applications of wave processes". Samara, 2003. - P. 401-402.

33. Gavrilov V. Yu., Matveev I. V., Osipov O. V. Quantumindeterminism as a determinant of higher nervous activity [Text]// Abstracts of reports and reports of the II scientific and technical conference "Physics and technical applications of wave processes". Samara, 2003. - P. 403-404.

34. Gavrilov V. Yu., Danilov A. A., Kalinin M. G., Neganov V. A. Automated medical and diagnostic complex [Text]// Abstracts of reports and reports of the II scientific and technical conference "Physics and technical applications of wave processes". Samara, 2003. - P. 406-407.

35. Gavrilov V. Yu. Biophysical aspects of cloning [Text]// Abstracts of reports and reports of the II scientific and technical conference "Physics and technical ap plications of wave processes". Samara, 2003. - P. 406-407.

36. Gavrilov V. Yu., Keltsev V. A., Limareva L. V., Makhova A. N., Neganov V. A., Osipov O. V., Pyatin V.F. System of technological solutions for remote control of processes in biological and cybernetic systems with a high level of selectivity [Text] // Abstracts of reports and reports of the II scientific and technical conference "Physics and technical applications of wave processes". Samara, 2003. - P. 408-410.

37. Gavrilov V. Yu., Keltsev V. A., Neganov V. A. Endovascular method of inducing information in clinical trials [Text]// Abstracts of reports and reports of the II scientific and technical conference "Physics and technical applications of wave processes". Samara, 2003. - P. 411 
38.Gavrilov V. Yu., Osip ov O. V. the Latest prospects for the application of a number of technologies based on the properties of chiral media [Text] // Abstracts of reports and reports of the II scientific and technical conference "Physics and technical applications of wave processes". Samara, 2003. - P. 412

39. Gavrilov V. Yu., Matveev I. V., Osipov O. V. On the question of non-local correlations [Text]// Abstracts of reports and reports of the II scientific and technical conference "Physics and technical applications of wave processes". Samara, 2003. - P. 413-414.

40. Certificate of registration and Deposit of the work-the object of copyright (related) rights no. A177. System of technological solutions for remote control of processes in biological systems and material objects and devices for its implementation [Text] / Gavrilov V. Yu., Volostnikov V. G., kolobaev M. V., Pavlyukova E. V., Osipov O. V., Kudinov V. G., Neganov V. A., Matveev I. V. Registered in the Register for no.A177 of June 23, 2004 LLC "law firm Gorodissky and Partners".

41. Certificate of registration and Deposit of the work-the object of copyright (related) rights no. A193. Principles of remote control devices for the functional state of material objects and quantum computer control system / Gavrilov V. Yu., Ginzburg Gabriel, kolobaev M. V. Registered in the Register for no. A193 of 12.11.2004 LLC "law firm Gorodissky and Partners".

42. Certificate of registration and Deposit of the work-the object of copyright (related) rights №231. Useful models (products) on the topic: "Interaction of electromagnetic waves and physically active media" [Text] / Gavrilov V. Yu., Danilov A. A., Erendeev Yu. P., Korelyakov B. V., Pryanikov I. V. 
Registered in the Register for no. J231CRT of 08.09.2005 LLC "law firm Gorodissky and Partners".

43. Certificate of registration and Deposit of the work-the object of copyright (related) rights No. 299. Useful models of composite chiral products for protection from negative factors of directed physical and geophysical processes of natural and artificial origin [Text]/ Gavrilov V. Yu., Neganov V. A., Osipov O. V., Pryanikov I. V. Registered in the Register for No. 1100299 of 07.02.2007 LLC "law firm Gorodissky and Partners".

44. Certificate of registration and Deposit of the work-the object of copyright (related) rights №300. Technology for recording and broadcasting information about the physical properties of material objects, based on a special method for processing crystals, semiconductors, etc. active media [Text] / Gavrilov V. Yu., Neganov V. A., Osipov O. V., Pryanikov I. V., savransky V. V. Registered in the Register for No. 1100300 of 07.02.2007 LLC "law firm Gorodissky and Partners".

45. Certificate of registration and Deposit of the work-the object of copyright (related) rights №303. Determination of physical and mathematical foundations for the development of management systems for environmental and geophysical parameters / Gavrilov V. Yu., Peshin S. V., Pryanikov I. V. Registered in the Register for No. 1100303 of 22.02.2007 LLC "law firm Gorodissky and Partners".

46. Certificate of registration and Deposit of the work-the object of copyright (related) rights № 319. Physically - and geometrically-chiral multilayer thin-layer metastructures[Text]/Gavrilov V. Yu., Neganov V. A., Osipov O. V., Pryanikov I. V., savransky V. V. Registered in the Register for No. 1100319 of 10.07.2007 LLC "law firm Gorodissky and Partners". 
47. Certificate of registration and Dep osit of the work-object of copyright (related) rights No. 333. Fractal artificial metastructures based on chiral composites [Text]/ Gavrilov V. Yu., Osipov O. V., Pryanikov I. V.

Registered in the Register for No. 1100333 of 26.10.2007 LLC "law firm Gorodissky and Partners".

48. Gavrilov V. Yu., Neganov V. A., Osipov O. V., Pryanikov I. V. Objective reality of the Torah. Moscow: science Press, 2008. -104 p.

49. Gavrilov V. Yu., Klyuev D. S., Neganov V. A., Osipov O. V., Pryanikov I. V. Mirror reality (nanometa). Samara: Gavrilov V. Yu., Klyuyev D. S., Neganov V. A., Osipov O. V., Pryanikov I. V. Mirror reality (nanometa) Samara: Volga state University of Telecommunications and Informatics, 2014. - $256 \mathrm{p}$.

50. Antipov O. I., Ardatov S. V., Gavrilov V. Yu. Methods of non-local stimulation of processes in biological objects based on new physical principles of action // Izvestiya Samara scientific center of the Russian Academy of Sciences, vol. 17, no. 5(3), 2015 P.715-719.

51. Kotelnikov G. P., Soyfer V. A., Antipov O. I., Ardatov S. V., Ardatova A. S., Gavrilov V. Yu., Dolgushkin D. A., Skidanov R. V. MODELING OF PROCESSES IN MATERIALENVIRONMENTS BASED ON NEW PHYSICAL PRINCIPLES OF ACTION ON THE EXAMPLE OF STIMULATION OF REPARATIVE OSTEOGENESIS//Scientific and technical journal «THEORY. PRACTICE. INNOVATIONS» Publisher: Vector of science limited liability Company (Sterlitamak), eISSN: 2500 3348. April - № 4, 2016. [Electronic resource,s] URL: https://www.elibrary.ru/item.asp?id=25920618 and URL: https://rf-chinascience.ru/wp-content/uploads/2017/01/Sodr_2_2.pdf 
52. Ardatov S. V., Ardatova A. S., Gavrilov V. Yu. On the question of new physical principles of action in physiotherapy procedures for stimulating accelerated reparative osteogenesis // Modern scientific research and innovation. 2019. № 1 [Electronic resource] URL: http://web.snauka.ru/issues/2019/01/88652 (accessed: 09.02.2019).

53. Ardatov S. V., Ardatova A. S., Gavrilov V. Yu. Convergent method of teleportation of States based on the nature-like use of biological objects // Modern scientific research and innovation. 2019. № 2 [Electronic resource]

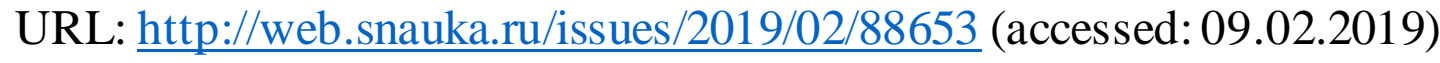

54. Ardatov S. V., Ardatova A. S., Gavrilov V. Yu., Gavrilova A.V. Scheme of information telep ortation in the mesoscopic (electrodynamic) space of events-the final of the trilogy // Modern scientific research and innovation. 2019. No. 4 [Electronic resource] URL: http://web.snauka.ru/issues/2019/04/89001 (accessed: 05.04.2019).

55. Antipov O. I., Ardatov S. V., Gavrilov V. Yu., Dolgushkin D. A., Evdokimov A. N., Korelyakov B. V., Skidanov R. V. on the issue of modeling probabilistic processes in nature-like aspects of physiotherapy technologies // Modern scientific research and innovation. 2019. № 5 [Electronic resource] URL: http://web.snauka.ru/issues/2019/05/89227 (accessed: 14.05.2019).

56. Ardatov S. V., Ardatova A. S., Vlasov Ya. V., Gavrilov V. Yu., Shchankina A.V. the Concept of creating functional $4 \mathrm{D}$ holographic loci of a new type of non-volatile memory - as a carrier and storage of various modes of preserved entangled quantum States // Modern scientific research and innovation. 2019. № 5 [Electronic resource] URL: http://web.snauka.ru/issues/2019/05/89228 (accessed: 14.05.2019). 
57. Ardatov S. V., Ardatova A. S., Vlasov Ya. V., Gavrilov V. Yu., Shchankina A.V. Summary of the concept of a holographic model of biophysical aspects of possible reproduction of the thesaurus of personality using a convergent quantum system (nature-like biocomputer)// Modern scientific research and innovation. 2019. № 5 [Electronic resource] URL: http://web.snauka.ru/issues/2019/05/89229 (accessed: 14.05.2019).

58. Antipov O. I., Antipova T. A., Ardatov S. V., Ardatova A. S., Vlasov Ya. V., Gavrilov V. Yu., Shchankina A.V. Some prospects of NBICS technologies in the develop ment of predictive, preventive and personalized medicine // Modern scientific research and innovation. 2019. № 8 [Electronic resource] URL: http://web.snauka.ru/issues/2019/08/90166 (accessed: 09.09.2019).

59. Priority reference: "A method for increasing the probability of complex processes occurring in quantum mechanical systems" [Text]/O. I. Antipov, S. V. Ardatov, V. Yu. Gavrilov [et al.]. - Federal Institute of industrial property (FIPS). Application: 2014149529,08.12.2014. Date the request was published: 10.07.2016. Bull. No. 19 .

60. Priority reference: "Method of remote modeling of reparative osteogenesis" [Text]/ O. I. Antipov, S. V. Ardatov, A. S. Ardatova [et al.]. - Federal Institute of industrial property (FIPS). Application: 2015105235, 16.02.2015. Date the request was published: 27.08.2016. building № 24 .

61. Priority reference: "Method for modeling coupled quantum States in medicine (variants)» [Text] / O. I. Antipov, S. V. Ardatov, A. S. Ardatova [et al.]. - Federal Institute of industrial property (FIPS). Application: 2015116054, 27.04.2015. Date the request was published: 20.11.2016. building № 32 . 
62. Akiko Tsumura Researchers teleport information within a diamond// JOURNAL Communications Physics/YOKOHAMA NATIONAL UNIVERSITYNEWS RELEASE, 28-JUN-2019 [Electronic resource] URL: https://eurekalert.org/pub_releases/2019-06/ynu-rti062519.php

63. Physics learned to telep ort macro objects / INFO. SIBNET. RU 10.03.16, RIA Novosti [Electronic resource] URL: https://info.sibnet.ru/article/469159/

64. Roman Schnabel Einstein-Podolsky-Rosen-entangled motion of two massive objects//Phys. Rev. A 92, 012126 - Published 28 July 2015 [Electronic resource] URL:

https://journals.aps.org/pra/abstract/10.1103/PhysRevA.92.012126

65. QUANTUMEFFECTS IN MESOSCOPIC SYSTEMS.Part 1 Quantum tunneling with dissipation. Textbook. [Electronic resource] URL: https://www.semanticscholar.org/paper/KВАНТОВЫЕ-ЭФФЕКТЫ-ВМЕЗОСКОПИЧЕСКИХ-СИСТЕМАХ.-Ч.1-с-ЖуковскийКревчик/ed87c0d8110a54ae5f0b6cfaa02b045ca41e1c6b

66. V. CH. Zhukovsky, V. D. Krevchik, M. B. Semenov, A. I. Ternov QUANTUMEFFECTS IN MESOSCOPIC SYSTEMS Part I. Quantum tunneling with dissipation/ Textbook for students of the faculty of physics Moscow state University faculty of Physics 2002. [Electronic resource] URL: $\underline{\text { http://window.edu.ru/resource/074/37074/files/stup273.pdf }}$

67. ROYAL SOCIETY PUBLISHING@RoyalSocietyPublishing.FanPage/ruRU.FACEBOOK.COM[Electronic resource] URL:

https://royalsocietypublishing.org/doi/full/10.1098/rsif.2018.0058 - Journal of the Royal Society Interface 
68. Guillaume Dezecache1, Chris D. Frith, Ophelia Deroy Pandemics and the great evolutionary mismatch// Journal pre-proof DOI: 10.1016/j. cub. 2020. 04.010 [Electronic resource] URL: https://marlinprod.literatumonline.com/pb-assets/products/coronavirus/Dezecache.pdf https://www.cell.com/current-biology/home

69. Montagnier, L., Aïssa, J., Ferris, S. et al. Electromagnetic signals are produced by aqueous nanostructures derived from bacterial DNA sequences. InterdiscipSciComputLifeSci 1, 81-90 (2009). https://doi.org/10.1007/s12539-009-0036-7

70. Temporary Defense Systems Purchases the First D-Wave 2000Q Quantum Computer [Electronic resource] URL: https://www.dwavesys.com/press$\underline{\text { releases/temporal-defense-systems-purchases-first-d-wave-2000q-quantum- }}$ computer

71. Steve Jurvetson Hot off the press - the latest D-Wave wafer of quantum processors and TIME cover story [Electronic resource] URL: https://www.flickr.com/photos/jurvetson/12369089904/

72. MIKE WHEATLEY,D-Wave Systems has sold its first 2,000-qubit quantum computer for $\$ 15 \mathrm{M}$ [Electronic resource] URL: https://siliconangle.com/2017/01/26/d-wave-systems-sold-first-2000-qubitquantum-computer-15m/

73. To speed computation, quantum computers tap directly into an an unimaginably vast fabric of reality - the strange and counterintuitive world of quantum mechanics. [Electronic resource] URL: https://www.dwavesys.com/quantum-computing 
74. QUANTUMANNEALING// MATERIALFROM WIKIPEDIA-FREE ENCYCLOPEDIA [Electronic resource] URL:

https://ru.wikipedia.org/wiki/Квантовый отжиг

75. THE task of a SALESMAN// MATERIAL from WIKIPEDIA-FREE ENCYCLOPEDIA [Electronic resource] URL:

https://ru.wikipedia.org/wiki/Задача коммивояжера

76. ABOUT THE STRENGTH AND WEAKNESS OF THE QUANTUM COMPUTER FROM GOOGLE [ELECTRONIC RESOURCE] URL: https://nplus1.ru/material/2015/12/15/D-wave

77. D-WAVE SYSTEMS PREVIEWS 2000-QUBIT QUANTUM SYSTEM [Electronic resource] URL: https://www.dwavesys.com/press-releases/dwave-systems-previews-2000-qubit-quantum-system

78. Manuela Zapka, Dominik Heyers, Christine M. Hein, Svenja Engels, NilsLasse Schneider, Jörg Hans, Simon Weiler, David Dreyer, Dmitry Kishkinev, J. Martin Wild \& Henrik Mouritsen Visual but not trigeminal mediation of magnetic comp ass information in a migratory bird - Nature. 461. - P. 1274-1277 (29 October 2009)| doi:10.1038/nature08528.

79. Schumann's RESONANCE // MATERIAL from WIKIPEDIA-FREE ENCYCLOPEDIA [Electronic resource] URL:

https://ru.wikipedia.org/wiki/Резонанс Шумана

80. SPACE OBSERVING SYSTEM / data of COMPLEX MONITORING IN the city of TOMSK/SHUMANOV RESONANCES [Electronic resource] URL: http://sosrff.tsu.ru/?page_id=7 
81. Schumann RESONANCE [Electronic resource] URL: http://dostoyanieplaneti.ru/5627-rezonans-shumana

82. DE BROGLIE WAVE / MATERIALFROM WIKIPEDIA-FREE ENCYCLOPEDIA [Electronic resource] URL: https://ru.wikipedia.org/wiki/Волна_де_Broglie

83. DE BROGLIE'S HYPOTHESIS. De BROGLIE WAVES [] URL: https://cito.mgsu.ru/COURSES/course781/files/pdf/teoria_21_4ast_1.pdf

84. DE BROGLIE'S HYPOTHESIS//Wave properties of microparticles of matter [Electronic resource] URL:

http://ens.tpu.ru/posobie_fis_kusn/Квантовая\%20оптика.\%20atomic\%20i \%20nuclear\%20physics.\%20Физика\%20элементарных\%20частиц/03 $\underline{1 . h t m}$

85. DE BROGLIE's HYPOTHESIS // MARTINSONL. K. SMIRNOV E. V. QUANTUMPHYSICS/BAUMAN Moscow state technical University [Electronic resource] URL: http://fn.bmstu.ru/dataphysics/library/physbook/tom5/ch2/texthtm1/ch2 1 htm

86. Baretto Lemos G., Borish V., Cole G. D., Ramelow S., Lapkiewicz R., Zeilinger A. Quantumimaging with undetected photons [Text] // Nature, 2014. - V. 512.- P. 409-412.

87. Antipova T. A., Ardatov S. V., Ardatova A. S., Vlasov Ya. V., Gavrilov V. $\mathrm{Yu}$. Review of some interdisciplinary approaches to the study of quantum information telep ortation in macro-and ecosystems of the biogeosphere// Modern scientific research and innovation. 2020. № 3 [Electronic resource] URL: http://web.snauka.ru/issues/2020/03/91665 (accessed: 21.03.2020). 
88. Accretion as the beginning and end of cosmic evolution - January 30, 2019 [Electronic resource] URL:https://zen.yandex.ru/media/vkosmo/akkreciia$\underline{\text { kak-nachalo-i-konec-v-kosmicheskoi-evoliucii-5c4e8ec7f6778500aecebfef }}$

89. ACCRETION//Big Russian encyclopedia [Electronic resource] URL: https://bigenc.ru/physics/text/4344475

90. Gravity - a byproduct of "quantum entanglement", not "space curvature" Around the World [Electronic resource] URL: http://round-theworld.org/?p=5155

91. QUANTUMENTANGLEMENT. MATERIALFROM WIKIPEDIAFREE ENCYCLOPEDIA [Electronic resource] URL: https://ru.wikipedia.org/wiki/Квантовая запутанность

92. QUANTUMENTANGLEMENT AND GRAVITY / / DECEMBER 18, 2013 С Полит.py,1998-2020, 1998-2020 [Electronic resource] URL: https://polit.ru/article/2013/12/18/ps_entanglement/

93. Karpenko. I. A. THEORY AND METHODOLOGY OF SCIENCE AND TECHNOLOGY - Philosophical interpretation of modern approaches to the creation of the quantum theory of gravity// Philosophy of Science and Technology 2018, vol. 23, no 1, pp. 54-67 DOI: 10.21146/2413-90842018-23-1-54-67 [Electronic resource] URL: https://iphras.ru/uplfile/root/biblio/ps/ps23_1/54_67.pdf

94. Yasuhiko Kamikubo, Atsushi Takahashi Paradoxical dynamics of SARSCoV-2 by herd immunity and antibody-dependent enhancement// Kyoto University, Kibi International University - Cambridge University - May 02, 2020 Version 1 DOI: 10.33774/coe-2020-fsnb3 [Electronic resource] URL: 
https://www.cambridge.org/engage/coe/articledetails/5ead2b518d7bf70019

\section{$\underline{51 \mathrm{c} 5 \mathrm{a} 5}$}

95. Physicists received a previously unseen type of matter from light// (C) 2020 Online edition «Вести.Ру»-26.09.2013 [Electronic resource] URL: https://www.vesti.ru/doc.html?id=1134707\&cid=2161

96. Brian Swingle. Spacetime from Entanglement/Annual Review of Condensed Matter Physics. Volume 9, 2018-pp. 345-358 [Electronic resource] URL: https://doi.org/10.1146/annurev-conmatphys-033117$\underline{054219}$

97. Christopher R. Moon, Laila S. Mattos, Brian K. Foster, GabrielZeltzer \& Hari C. Manoharan Quantum holographic encoding in a two-dimensional electron gas/Nature Nanotechnology. Volume 4, 2009 - p.167-172/ [Electronic resource] URL:

https://www.nature.com/articles/nnano.2008.415

98. Poincaré H. La théorie de Lorentz et le principe de réaction (French)// Archives néerlandaises des sciences exactes et naturelles - - 1900. - Vol. 5. - P. 252-278

99. Perelman, Grisha (November 11, 2002), the entropy formula for the Ricci flow and its geometric ap plications, arXiv:math.DG/0211159 [math. DG]

100. Perelman, Grisha (March 10, 2003), Ricci flow with surgery on threemanifolds, arXiv:math.DG/0303109 [math.DG] 
101. Perelman, Grisha (July 17, 2003), Final extinction time for the solutions to the Ricci flow on certain three-manifolds, arXiv:math.DG/0307245 [math.DG]

102. Bo-Sture K Skagerstam, Karl-Erik Eriksson and Per K Rekdal Causality in quantumfield theory with classical sources//Journal of Physics Communications. 3 (2019) 8, 082001 DOI: 10.1088/2399-6528/ab3c1c [Electronic resource] URL: https://inspirehep.net/literature/1651252 